\title{
Discussion on the Feasibility of Idle Schoolhouse Reconstruction for Elderly Care Facilities in Rural Areas
}

\author{
Jin Zhang \\ School of Architecture and Civil Engineering \\ Zhongyuan University of Technology \\ Zhengzhou, China
}

\author{
Gaihong Chang \\ School of Architecture and Civil Engineering \\ Zhongyuan University of Technology \\ Zhengzhou, China
}

\begin{abstract}
China has accelerated its pace to an aging society since 1999, and how to make the aged live a better life is a problem increasingly serious to solve. Especially for those living in rural areas, who are not as good as we expect, the empty-nest old people are in a large number and there are no adequate old-age pensions applicable as well as the lack of facilities for eldercare. In the meantime, a great number of primary and middle school buildings in rural areas have been left unused due to the advancement of urbanization and the "schools repeal and merger" policy across the country, and it is considered possible to make full use of the school buildings for the elder-oriented reconstruction, which may be an economical and rapid way for the construction of facilities for eldercare.
\end{abstract}

Keywords-idle schoolhouse; elders-oriented reconstruction; feasibility

\section{INTRODUCTION}

Before the 1980s, primary and middle schools were planned and built under the principle of "one primary school in one village and one middle school in one town" in rural areas in China. In order to further optimize the resource allotment for the rural education, the "one school in on village" mode was rejected in rural areas starting from the year 2001, and the schools nearby were merged, consequently a good many primary and middle school buildings were left unused, which, difficult to manage, were thought a waste of resources.

In addition, after 1999, China began to accelerate its pace to an aging society, and the eldercare has been an urgent problem to solve, especially most of the elders live in rural areas, which causes it more difficult for them to live, for most of young people have left villages for cities, there are more and more empty-nest older people in villages, and traditional family-based eldercare mode has been far to take the mission for the eldercare in rural areas, so to push the eldercare to the market is an inevitable trend for the eldercare in rural areas. However, there is another fact in bad situation, compared to cities, the old-age pension and facilities for the elders are in an inadequate and poor condition, which is a very bottleneck restricting the eldercare in rural areas.

Project title: Research on Henan Beautiful Rural Eldercare Facilities D esign, Number: 162400410569
A survey made by the author in Henan provinces shows, some school buildings are changed to mutual-support nursing homes, and no doubt it is an economical and rapid way to solve the problem.

\section{PRIMARY AND Middle SChOOl Buildings ARE LEFT UNUSED IN RURAL AREAS}

\section{A. Loss of School Age Children in the Compulsory Stage in Rural Areas}

Going with the conversion of education concepts in rural areas, more and more parents start to value the children education. Seeing the difference in teaching quality, faculties and facilities between rural and urban areas, parents in rural areas start to select schools for their children, and students flow to schools with quality education from those with poor infrastructures, and the students increasingly leave rural areas for towns, suburbs and downtown areas. In the meantime, most school age students come from single-child families, whose numbers are less compared to that before, besides, more and more farmers move to cities with their children taken to study there. All of these have led to the loss of most students in rural areas, especially those which are poor in economy and educational resources, as a result, the schools concerned are in a great trouble to survive.

\section{B. Shutdown of A Great Number of Primary and Middle Schools under the "School Repeal and Merger" Policy}

Early in the 1990s, the "school repeal and merger" already appeared, and the State Council of China released Decision of the State Council on Basic Education Reform and Development in 2001, which pointed out that the layout of compulsory education in rural areas should be adjusted on the basis of local conditions, raising a "school repeal and merger" policy. From then on, during a decade of 2000-2010, there were about 63 primary schools, 30 teaching departments and 3 middle schools averagely shut down ever day and 4 schools ended almost per hour. ${ }^{1}$ During the period, about 229,400 primary schools were shut down in rural areas, accounting for $52.1 \%$ of the total, and about 111,000 teaching departments ended, accounting for about $60 \%$ of the

\footnotetext{
${ }^{1}$ Source: Report of a Decade Adjustment of Educational Layout in Rural Areas released by $21^{\text {st }}$ Century Education Research Institute
} 
total; about 10,600 middle schools were shut down in rural areas, at a speed of $25 \%$, consequently almost half of schools in rural areas have been left unused.

\section{MORE DIFFICULT FOR THE EMPTY-NET OLD PEOPLE TO BE CARED FOR IN RURAL AREAS}

\section{A. Trend and Status Quo of the Eldercare in Rural Areas}

Data of the 6th national census made in 2010 show, there were about 100 million old people living in rural areas, accounting for $55.90 \%$ of the total old people throughout the country, and the old people were increasing rapidly in rural areas. ${ }^{2}$ Compared to cities, the aging population in rural areas features large population base, rapid speed to increase, undeveloped economic conditions and poor infrastructures.

In addition, the acceleration of urbanization in the country has attracted a great number of young laborers to cities from rural areas, and more and more old people are left home in rural areas, thus the young people leaving and the old-people left families are becoming more serious than ever. And the long-distance separation between children working in cities and parents left home have caused the failure of children to care for parents, unable to meet what the old people need "Fig. 1".

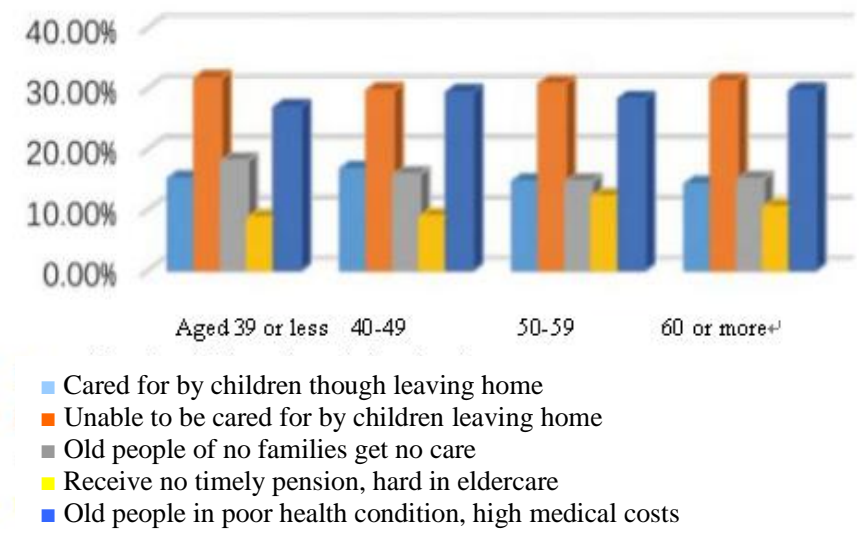

Fig. 1. Problems of eldercare in rural areas.

In the meantime, the old people left home are faced with problems such as heavy housework, living in a hard life, lack of caregivers when being ill, accompanied by nobody when going outside and others "Fig. 2", which have finally led to loneliness of the old people, lack of spiritual comfort, hopeless to live and more. The family-based eldercare is worsened and traditional family-based eldercare is unable to continue the eldercare, and it is inevitable that the eldercare should be pushed to the market in rural areas.

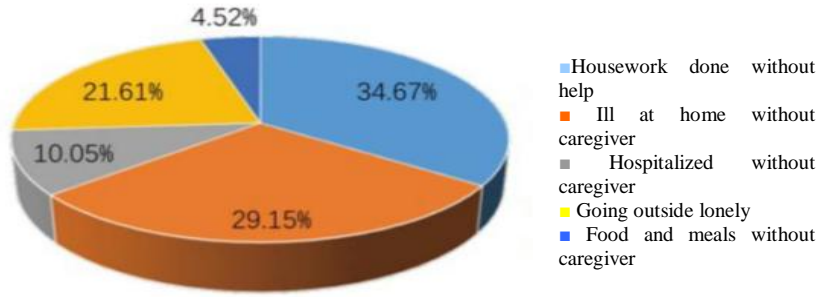

Fig. 2. Problems old people aged 60 or more meet in living.

However, there is another problem to face seriously, the old-age pension funds are extremely inadequate as well as poor facilities for the eldercare.

\section{B. Expectation of Old People in Rural Areas, Staying at Home for Eldercare}

Traditionally the old people in rural areas expect to be cared for in families, namely it is called being cared care by children. The family pension means that after losing labor abilities, old people would stay with and be cared for by children or grandchildren in their families. Supported by the traditional moral ideas, the thought of "cared for by children" is deeply rooted. If the old people are separated from families for eldercare, their children will be considered filial. In villages, the people are living in a society where they are familiar and steady in blood, location and relative, owning emotions hard to give up. Therefore, main features for the eldercare in rural areas are "staying at home for eldercare", even it is hard to be cared for at home, they will still stay in villages of their own.

The author makes questionnaires in Jiyuan, Wuyang and Lankao, which prove the fact as well. Most think that the optimal mode for the eldercare in rural areas shall be "cared for at home" or the combination of "cared for at home" and social pension organizations "Fig. 3". If having to stay in a nursing home, most expect that the nursing home is expected to near the families, besides, the older the old people grow, the stronger the expectation is "Fig. 4".

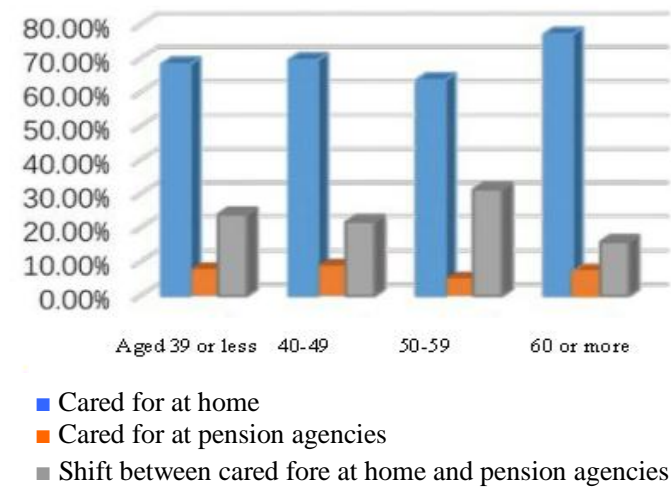

Fig. 3. Ideal mode for eldercare in rural areas

\footnotetext{
(2) Source: The $6^{\text {th }}$ National Census Bulletin posted by http://www.gov.cn.
} 


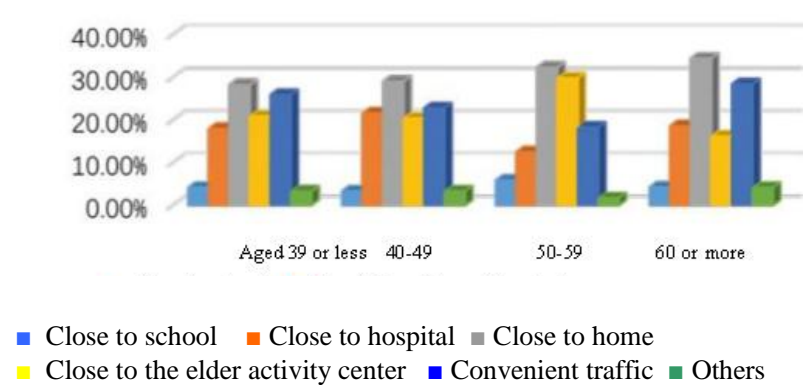

Fig. 4. Where facilities for eldercare are to be built.

\section{FEASIBILITY OF THE ELDERS-ORIENTATED} RECONSTRUCTION OF IDLE SCHOOL BUILDINGS IN RURAL AREAS

During the survey on facilities for the eldercare in Henan province, the author finds that most facilities sourced from the former primary and high school buildings such as Dongbatou Nursing Home at Lankao, Xizheng Village Nursing Home at Wulongkou Town, Jiyuan, Hepo Village Nursing Home, Quyang Lake Older People Apartment at Chengliu Town, Jiyuan and so on. Here the author takes Xizheng Village Nursing Home and Hepo Village Nursing Home as examples to discuss the feasibility of reconstructing school buildings left unused into nursing homes.

\section{A. Feasibility of Location}

1) Satisfy the requirements of old people to be cared for at home: Early in the 1980s, the "one school for one village and enrolling nearby" policy was carried out in most villages across the country, and most counties even pointed out that schools should be reachable within $2.5 \mathrm{~km}$ at most to villages. Therefore, the schools left unused all stand in villages most of which are located at the village center or entrance to it. The locations are favorable for the old people to stay at homes, villages, relatives and homelands for eldercare. Xizheng Village Nursing Home and Hepo Village Nursing Home "Fig 5", "Fig. 6".

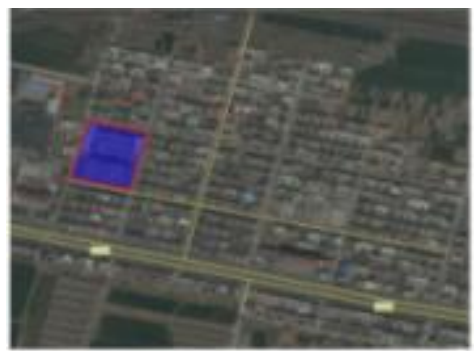

Fig. 5. Location of Xizheng Village Nursing Home.

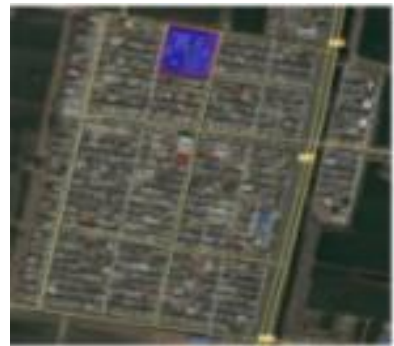

Fig. 6. Location of Hepo Village Nursing Home.

2) There are enough spaces outside the idle school buildings: Many provisions such as Code for Design of Primary and Middle Schools have requirements on per capita area, day lighting, building density and plot ratio relative to schools, therefore, generally the schools left unused are rich in land and supported with large lands for activities. For example, though accessory east to west houses are built on two sides of main buildings at Hepo Village Nursing Home and Xizheng Village Nursing Home, yet the large areas before the former main buildings are planted with flowers and grass, which make it easy for old people to participate in collective activities, so as to make the empty-nest old people be rich in spirit. In addition, the areas remained will be used for exercises for the old people "Fig. 7", "Fig. 8" and "Fig. 9".

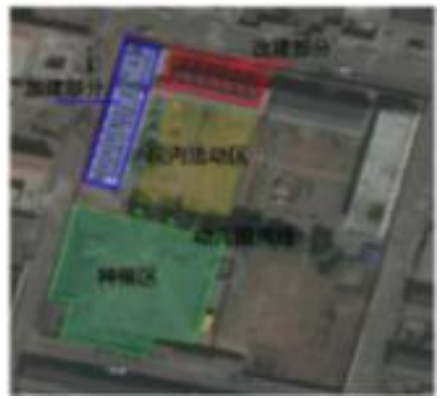

Fig. 7. General layout of Hepo Village Nursing Home.

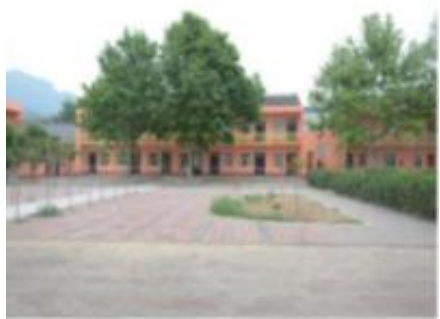

Fig. 8. Interior of Hepo Village Nursing Home.

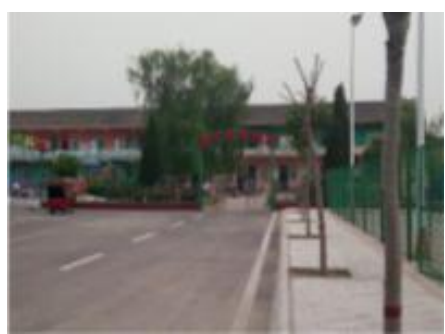

Fig. 9. Interior of Xizheng Village Nursing Home. 
3) It is flexible for reconstruction of architectural structure and house size: Architectural structures of primary and middle school buildings are mostly masonry structure and frame structure. In case of any reconstruction, the frame structures have advantages whether in flexibility, work capacity, civil work costs and so on. As for the eldercare projects at Xizheng Village and Quyang Lake, a large space is divided into two or three small spaces with proper doors added as well as reinforcement "Fig. 10", "Fig. 11", "Fig. 12 " and "Fig. 13", which are a little easer than other projects for reconstruction. It is true that if the school buildings are of masonry structure, it will be more difficult than the frame structures, which shall be classified carefully and reconstructed if possible.

The Standards for Construction of Primary and Middle School Buildings in Rural Areas provides, the classroom area at non-complete primary schools in rural areas shall be $40 \mathrm{~m} 2$ at least each, and the complete primary schools $54 \mathrm{~m} 2$ at least, and the classroom area at middle school shall be $61 \mathrm{~m} 2$ at least, which is a good point for the reconstruction for the eldercare, and the classrooms can be reconstructed into double-room, single room and so on according to current sizes, or toilets or balconies can be designed. For example, toilets are added to the oil-people apartment at Quyang Lake Apartment "Fig. 12", "Fig. 13".

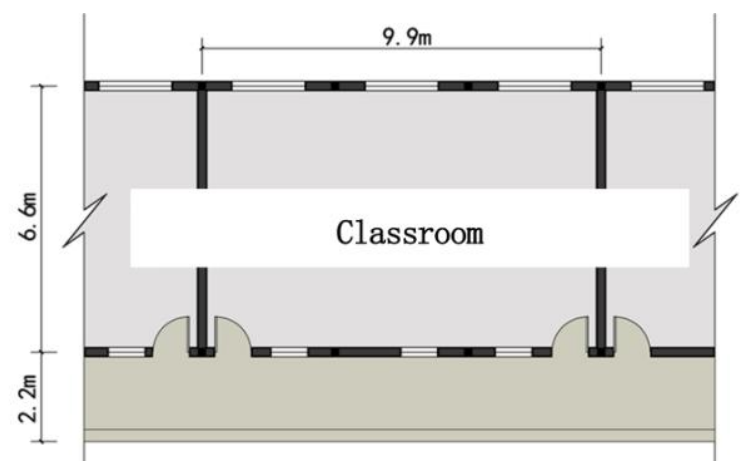

Fig. 10. Before (Xizheng Village)

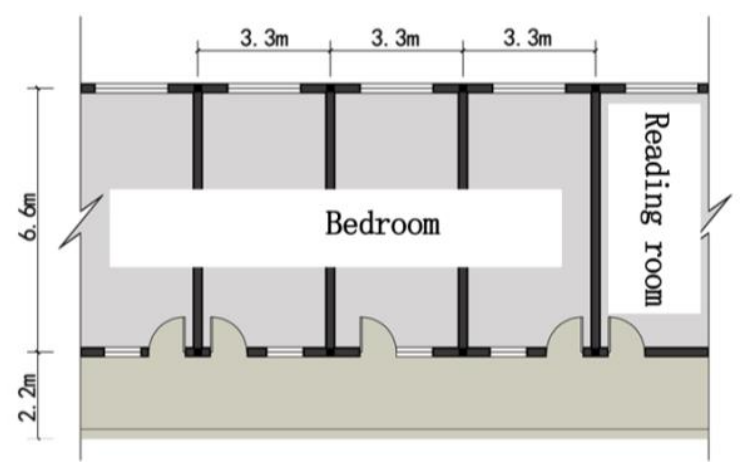

Fig. 11. After (Xizheng Village)

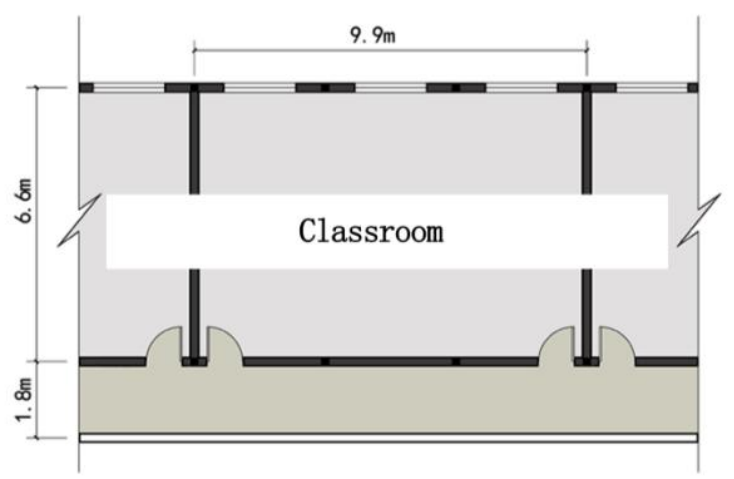

Fig. 12. Before (Quyang Lake)

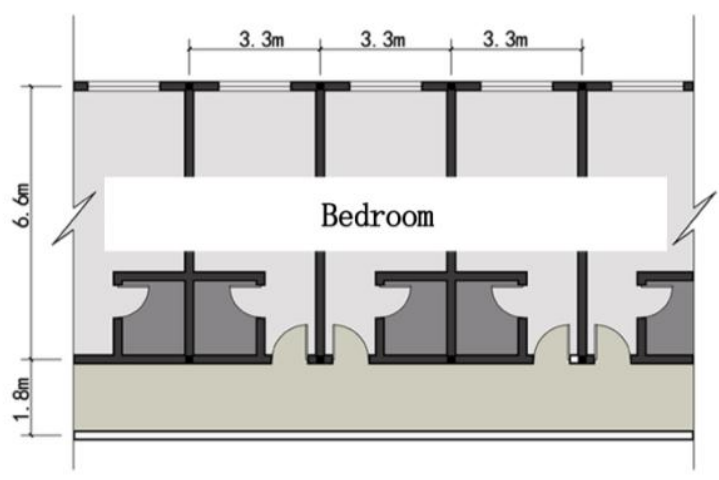

Fig. 13. Before (Quyang Lake)

Additionally the storey height of school buildings are also restricted and the storey height of general classrooms shall be not less than $3.6 \mathrm{~m}$, which makes it easy for the reconstruction of indoor ceiling and fire protection systems.

\section{CONCLUSION}

The elders-oriented reconstruction of school buildings left unused in rural areas have diverse advantages: On the one hand, originally the school buildings are owned by collectives, besides, the facilities will be based on and managed by the village committee, there will be no administrative barriers such as changes or transfer to ownerships; on the other hand, compared to other buildings in rural areas, the natural advantages of school buildings in rural areas make it more better to be reconstructed into bedrooms which need less civil work, and the costs are lower than the construction of new buildings; the construction period will be shorter, avoiding the waste of existing resources and popular by the old people in villages. Therefore, facing the severe condition where the facilities for eldercare are poor in rural areas, it will be a method economical and rapid to reconstruct the school buildings left unused for the old people.

\section{REFERENCES}

[1] The Ministry of Education, Schools Left Unused in Rural Areas across China, Statistic Data, 2000 2013 
[2] Mou Biao, Li Zhongguo, Discussion on Recycling of Schools Left Unused in Rural Areas [J] Beijing: Journal of Agriculture, 2015.5(4): 127-134

[3] Yan Shengxue, Li Baofeng and Xu Rui, Research on Demand Orientated Design and Integration of Schools Left Unused in Rural Areas [J] Hubei: Hubei Institute of Fine Arts, 2015.NO.02

[4] Shi Ke, Zhang Na, Thoughts About Recycling of Primary and Middle Schools Left Unused in Rural Areas [J] Beijing: Education Research, Vol.7, 2011

[5] Zhou Juan, Zhang Lingling, Is Nursing Home Optimal for the Eldercare in Rural Areas? China Rural Survey, May 2016

[6] Ma Xin, Research on Mutual Support-Based Eldercare in Rural Areas, taking Feixiang Town Mutual Support-Based Nursing Home, Hebei Province as an example, Master's Thesis of Hebei University, 2014

[7] Zhao Zhiqiang, Dilemma and Strategies for Mutual Support-Based Eldercare in Rural Areas, Journal of Hebei University (Philosophy and Social Science), Vol. 1, 2015. 